\title{
Grand Challenges in Sustainable Cities and Health
}

\author{
Sotiris Vardoulakis ${ }^{1 *}$ and Patrick Kinney ${ }^{2}$ \\ ${ }^{1}$ National Centre for Epidemiology and Population Health, Research School of Population Health, Australian National \\ University, Canberra, ACT, Australia, ${ }^{2}$ Department of Environmental Health, Boston University School of Public Health, \\ Boston, MA, United States
}

Keywords: urban health, climate change, environmental pollution, sustainable urban design, sustainable transport, health equity

\section{INTRODUCTION}

The size of global urban population has increased exponentially since the advent of the industrial revolution, with urban centers attracting large numbers of workers and families looking for opportunities for employment, education and better quality of life. The growth of large urban centers initially in Europe and North America was followed by even larger megacities in Latin America, Asia and Africa. Currently, more than half of the world's population lives in cities, with this figure projected to reach two-thirds of the world's population by 2050 .

Historically, urban populations have on average been healthier and more affluent compared to their rural counterparts. Improvements in education, housing, and public health (including better hygiene and sanitation), and better access to primary care (including wider vaccination coverage) resulted in longer life expectancy and healthier populations. However, as infectious diseases and malnutrition declined in many cities, non-communicable diseases (NCDs), including physical and mental illness, became more prevalent. Currently, rapid urbanizing countries around the world are facing an NCD epidemic with high rates of obesity, diabetes, cardiovascular illness and cancers associated with sedentary lifestyles, unhealthy diets, and environmental pollution (Leon, 2008; The Lancet, 2012).

Although population health in cities has generally improved, not everybody has benefited from these improvements. People living in urban slums, as well as socioeconomically deprived and migrant populations, have been disproportionally affected by pollution, climate extremes, and lack of clean water and sanitation, particularly in low and middle-income countries. This can create a "double burden" of communicable and non-communicable diseases for these disadvantaged urban populations (Sverdlik, 2011). The elderly, young children, and those with pre-existing illness are more vulnerable to extreme temperatures, floods, and pollution affecting cities (Hajat et al., 2007). People living in urban centers are disproportionately exposed to heat due to the Urban Heat Island effect (i.e., higher ambient temperatures in built up areas compered to surrounding suburban and rural areas) and building overheating (Heaviside et al., 2017). These factors conspire to create significant health and environmental inequities across generations, socioeconomic strata, and urban areas.

Rapid urban development has exacerbated environmental problems linked with unsustainable transport, housing, waste, energy, and land use management. Exposure to urban pollution (in air, water, and soil) has been associated with increased cardiovascular and respiratory mortality and morbidity and cancer incidence. For example, long-term exposure to urban air pollution shortens lifespans (Pope et al., 2009), and reduces lung growth in children (Gauderman et al., 2015). Short-term exposure to air pollution has been associated with increased daily mortality in cities (Liu et al., 2019) and asthma exacerbations in children (Bouazza et al., 2018). Overall, exposure to outdoor and indoor air pollution accounts for about 1 in 9 deaths every year worldwide 
(World Health Organization, 2016a). Outdoor particulate air pollution causes around $4.2 \mathrm{~m}(3.7-4.8 \mathrm{~m})$ premature deaths annually worldwide, with over $50 \%$ of them in India and China. Indoor air pollution, mainly associated with burning solid fuel for cooking or heating, accounts for around $2.9 \mathrm{~m}(2.2-3.6 \mathrm{~m})$ premature deaths annually, with much of the burden falling on women and young children in low and middle-income countries (Global Burden of Disease, 2016).

Climate change and related (more frequent and intense) extreme weather events, such as heatwaves and floods, in conjunction with demographic change, have exacerbated NCD mortality and morbidity in cities, with the elderly being more severely affected (Vardoulakis et al., 2014). Heatwaves have affected cities across the income spectrum, including some of the highest income world capitals. For example, $506( \pm 51)$ heatrelated deaths in Central Paris and $64( \pm 3)$ in Greater London were attributed to anthropogenic climate change during the summer of 2003 (Mitchell et al., 2016).

On the other hand, cities are often centers of policy and technological innovation and economic development. They are in many cases developing and implementing solutions to current public health and environmental problems associated with climate change, pollution, and unsustainable use of natural resources. For example, compact cities can help reduce car dependency and minimize the use of energy for transport (Dieleman et al., 2002). Sustainable transport systems and housing can save energy and minimize emissions of pollutants and greenhouse gases (Haines and Ebi, 2019). Increased active travel (i.e., more walking and cycling) and reduced red and processed meat consumption can directly improve cardiovascular health, as well as reduce greenhouse gas emissions (Haines et al., 2009). Well-designed and maintained urban vegetation and high reflectance roofs can help reduce the Urban Heat Island effect and building overheating (Salmond et al., 2016).

The UN Sustainable Development Goals (SDGs), the UN New Urban Agenda, and the WHO Urban Health Initiative (World Health Organization, 2016b, 2019) have focused the attention of researchers, practitioners and decision-makers on policies and interventions that have the potential to provide multiple benefits for health, the environment, and the economy in urban settings. However, more scientific evidence is needed to evaluate policies and interventions and underpin innovation that will improve health in cities. A number of international projects, activities and networks have raised awareness of the challenges and opportunities facing cities and health focusing on the need for inter-disciplinary systems based thinking (Vardoulakis et al., 2016).

Low-cost sensor technologies, crowd sourcing, social media, and mobile applications have enabled active involvement of urban populations in "citizen science" projects, e.g., by collecting and linking environmental and health data. In addition to raising awareness, citizen science together with innovative big data analysis, linkage and visualization methods open up opportunities for stronger and more interactive engagement with stakeholders at all levels of urban governance (Buytaert et al., 2014; Fleming et al., 2014; Den Broeder et al., 2018). The recently proposed "urbanome" framework (i.e., a complete set of data describing the physical, social, operational, and structural characteristics of a city) aiming to characterize cities and people living in them in a holistic manner can further enhance our ability to diagnose problems, identify actionable solutions and test future scenarios, policies and interventions using a holistic systems approach (Morawska et al., 2019).

\section{GRAND CHALLENGES}

A lot of scientific effort has traditionally concentrated in characterizing associations between environmental and behavioral risk factors and health outcomes. This has included, for example, the effects of different air pollutants (as well as pollutant mixtures), high and low temperatures, noise, diet, physical activity, and proximity to greenspace on noncommunicable diseases (Mitsakou et al., 2019). Novel assessment techniques have been increasingly used in these studies. For example, "multi-hazard" and "exposome" approaches have been introduced to assess human exposure in different environments over the life-course (Juarez and Matthews-Juarez, 2018). These approaches have helped characterize health effects from chronic (low-level or intermittent) exposures to a variety of chemical or physical hazards in cities. However, less research has focused on evaluating policies and interventions aiming to improve the health and environment of urban dwellers. In particular, there is a dearth of observational studies that can strengthen the evidence on the effectiveness of interventions, including barriers and enablers for successful implementation, in different geographic and socioeconomic contexts. In this article, we are aiming to outline grand challenges for science and innovation that will promote health and sustainability in cities around the world.

\section{Urban and Transport Planning}

Land use planning and urban form have a strong influence on transport and accessibility, and consequently on traffic-related air pollution, sedentary lifestyles, noise and GHG emissions and associated effects on health. Reallocation of road space, road closures, cycle paths, and the creation of pedestrian areas can all promote active (walking and cycling) and public transport in cities. Specific measures to reduce congestion and road traffic emissions, e.g., Low Emission Zone, car, bike and scooter sharing systems, Congestion Charging Zones, Clean Air Zones, and other road use pricing, parking and access restriction schemes have been introduced in many cities (Wang et al., 2016; Vardoulakis et al., 2018). These measures have the potential to provide substantial health benefits associated with improved physical activity, community cohesion and road safety, and reduced air pollution, GHG emissions and noise. However, unintended negative effects are also possible, e.g., migration of polluting sources, road injuries or exacerbation of health inequities, if the measures are not well-designed or implemented. There is therefore a need for comprehensive studies examining the effectiveness, co-benefits and unintended consequences, of such interventions. Although modeling studies have shown promise, there is currently a lack of observational 
studies that holistically assess the health benefits/impacts of realworld planning interventions using system-based approaches.

\section{Built and Indoor Environment}

We spend most of our time in indoor environments (house, school, office) which determine to a large extent our exposure to chemical and biological contaminant, our vulnerability to extreme weather (heat, cold, floods), and consequently our physical and mental health and well-being. The built environment is very complex and requires holistic solutions that take into account the multiple interrelated factors that determine indoor environmental quality. Poor indoor environmental quality may be due to inadequate ventilation, indoor pollution sources (including biomass burning for cooking and heating in low income settings), overheating, poor lighting, mold, and noise (Wu et al., 2007). Furthermore, demographic and climate change are likely to alter many of these risks in the future (Vardoulakis et al., 2015), particularly in rapidly urbanizing environments. Co-benefits and trade-offs for health may arise where action to reduce GHG emissions and adapt to climatic extremes lead to changes in the building fabric, ventilation, air conditioning, or energy usage.

\section{Green and Blue Infrastructure}

There is increasing recognition that proximity to, and interaction with, urban green and blue spaces can have a significant benefits on our health and well-being. A number of mechanisms have been identified, including localized cooling, noise abatement, water purification, flood risk reduction, and improved physical activity and mental health. Urban green infrastructure has also been associated with several environmental and societal cobenefits, such as air pollution and climate change mitigation (i.e., vegetation has the capacity to remove carbon dioxide, gaseous pollutants, and airborne particles) and cultural-aesthetic and recreational benefits (Salmond et al., 2016). On the other hand, potential negative effects include emissions of pollen and volatile organic compounds, urban ticks, safety concerns, and energy input and cost of maintenance of urban green spaces. The ecosystem services approach has increasingly been used to evaluate the benefits of green and blue infrastructure in cities (Hansen et al., 2015; Salmond et al., 2016). But there is an urgent need for better knowledge on how to design urban green spaces that maximize both environmental and human health benefits.

\section{Urban Food Systems}

The ecosystem services approach can also be used to assess the multiple dimensions of urban food systems, including healthy diets, food safety and security, and urban food infrastructure (for food production, storage, and distribution). Low red meat diets can substantially reduce greenhouse gas emissions from livestock farming and simultaneously provide health benefits associated with reduced saturated fat consumption (Friel et al., 2009).

Linking urban and rural food supply is essential for optimizing the complex food production and consumption system. However, greater quantities of food grown in urban areas could be of concern because of their higher risk of legacy contamination in urban soils (Lake et al., 2012). Holistic perspectives are clearly needed to maximize the benefits of healthy, low-carbon, resilient urban food systems, minimize related health inequalities and other potential dis-benefits (e.g., food waste), and manage emergencies associated with climate extremes.

\section{Sustainable Energy and Waste Management}

Urbanization and raising living standards are projected to increase energy demand and waste generation, particularly in rapidly urbanizing low and middle-income countries of Asia and Africa. China has become the largest generator of municipal solid waste in the world with its rapid urbanization, population growth and raising living standards (Wang et al., 2018). Unsustainable patterns of consumption, energy and waste generation in cities have negative consequences for population and environmental ("planetary") health (Gupta et al., 2019). There is an urgent need for evidence-based solutions for more sustainable energy and waste management in cities. Urban energy solutions require full life cycle analysis, taking into account the full spectrum of positive and unintended negative impacts of transition to renewable energy (Scovronick et al., 2019). The circular economy, which aims to minimize waste by making the most of available resources, has the potential to generate environmental, health and societal benefits in cities that are currently not fully appreciated.

\section{Urban Health Equity}

Health equity is a crosscutting issue, and emerging research theme, in urban sustainability studies. Climate change, pollution, inadequate housing, and unsustainable production and consumption are threatening environmental justice and health equity across generations, socioeconomic strata, and urban settings. Vulnerable groups (young children, the elderly, the poor, and those with compromised health) are likely to suffer more from environmental pollution and climate extremes, such as heatwaves, floods and droughts. These groups also have the most to gain from well-designed interventions to improve urban environmental quality. Certain urban policies and interventions may reduce, or inadvertently exacerbate, inequalities; therefore they require careful impact assessment across the population (Costa et al., 2019). More gender and age-sensitive strategies can help address inequities in urban health, particularly between those living in informal settlements and other urban residents (Sverdlik, 2011).

\section{FUTURE DIRECTIONS}

Technological advancements in sustainable transport, energy and waste management, zero carbon building design, pollution abatement, urban food systems, wearable sensors, mobile applications, and big data analysis provide opportunities to improve the health of urban populations while reducing their pollution and carbon footprint. However, technology solutions alone are unlikely to solve the persistent environmental, societal and health problems that twenty-first century cities are facing around the world. To achieve sustainable, long-term solutions 
we need concerted action from key stakeholders-government, planners, health professionals, researchers, businesses-as well as individual citizens. Importantly, we need to develop a better understanding of complex societal, technological and behavioral barriers and enablers for effective change toward healthier and more sustainable cities. This requires holistic, system-based approaches that address multiple environmental and health hazards, taking into account co-benefits, and unintended consequences.

The challenges of translating the emerging science of urban health into effective policy are complex. Over-emphasizing a single process, such as building energy or vehicle fuel consumption, can have unintended consequences, for

\section{REFERENCES}

Bouazza, N., Foissac, F., Urien, S., et al. (2018). Fine particulate pollution and asthma exacerbations. Arch. Dis. Childhood 103, 828-831. doi: 10.1136/archdischild-2017-312826

Buytaert, W., Zulkafli, Z., Grainger, S., Acosta, L., Bastiaensen, J., De Bièvre, B., et al. (2014). Citizen science in hydrology and water resources: opportunities for knowledge generation, ecosystem service management, and sustainable development. Front. Earth Sci. 2:26. doi: 10.3389/feart.2014.00026

Costa, C., Santana, P., Dimitroulopoulou, S., Burstrom, B., Borrell, C., Schweikart, J., et al. (2019). Population health inequalities across and within European Metropolitan Areas through the lens of the EUROHEALTHY population health index. Int. J. Environ. Res. Public Health 16:836. doi: 10.3390/ijerph16050836

Den Broeder, L., Devilee, J., Van Oers, H., Schuit, A. J., and Wagemakers, A. (2018). Citizen science for public health. Health Promot. Int. 33, 505-514. doi: 10.1093/heapro/daw086

Dieleman, F. M., Dijst, M., and Burghouwt, G. (2002). Urban form and travel behaviour: Micro-level household attributes and residential context. Urban Stud. 39, 507-527. doi: 10.1080/00420980220112801

Fleming, L. E., Haines, A., Golding, B., Kessel, A., Cichowska, A., Sabel, C. E., et al. (2014). Data mashups: potential contribution to decision support on climate change and health. Int. J. Environ. Res. Public Health 11, 1725-1746. doi: 10.3390/ijerph110201725

Friel, S., Dangour, A. D., Garnett, T., Lock, K., Chalabi, Z., Roberts, I., et al. (2009). Public health benefits of strategies to reduce greenhouse-gas emissions: food and agriculture. Lancet 374, 2016-2025. doi: 10.1016/S0140-6736(09)61753-0

Gauderman, W. J., Urman, R., Avol, E., Berhane, K., McConnell, R., Rappaport, E., et al. (2015). Association of improved air quality with lung development in children. N. Engl. J. Med. 372, 905-913. doi: 10.1056/NEJMoa1414123

Global Burden of Disease (2016). Global, regional, and national comparative risk assessment of 79 behavioural, environmental and occupational, and metabolic risks or clusters of risks, 1990-2015: a systematic analysis for the Global Burden of Disease. Lancet 388, 1659-1724. doi: 10.1016/S0140-6736(16)31679-8

Gupta, J., Hurley, F., Grobicki, A., Keating, T., Stoett, P., Baker, E., et al. (2019). Communicating the health of the planet and its links to human health. Lancet Planet Health 3, e204-e206. doi: 10.1016/S2542-5196(19)30040-3

Haines, A., and Ebi, K. (2019). The imperative for climate action to protect health. N. Engl. J. Med. 380, 263-273. doi: 10.1056/NEJMra1807873

Haines, A., McMichael, A. J., Smith, K. R., Roberts, I., Woodcock, J., et al. (2009). Public health benefits of strategies to reduce greenhouse-gas emissions: overview and implications for policy makers. Lancet. 374, 2104-2114. doi: 10.1016/S0140-6736(09)61759-1

Hajat, S., Kovats, R. S., and Lachowycz, K. (2007). Heat-related and cold-related deaths in England and Wales: who is at risk? Occup. Environ. Med. 64, 93-100. doi: 10.1136/oem.2006.029017

Hansen, R., Frantzeskaki, N., McPhearson, T., Rall, E., Kabisch, N., Kaczorowska, A., et al. (2015). The uptake of the ecosystem services concept in planning example on indoor or outdoor air quality. Furthermore, a place-based understanding of potential impacts and opportunities for health improvement that takes into account the social and cultural context of cities around the world is required for developing effective solutions. Importantly, this requires effective public, policy, and business engagement to ensure translation of scientific outputs into actionable long-term solutions.

\section{AUTHOR CONTRIBUTIONS}

SV drafted the article. SV and PK contributed intellectual input, text, and edits. discourses of European and American cities. Ecosystem Serv. 12, 28-246. doi: 10.1016/j.ecoser.2014.11.013

Heaviside, C., Macintyre, H., and Vardoulakis, S. (2017). The Urban Heat Island: implications for health in a changing environment. Curr. Environ. Health Rep. 4, 296-305. doi: 10.1007/s40572-017-0150-3

Juarez, P. D., and Matthews-Juarez, P. (2018). Applying an exposomewide (ExWAS) approach to cancer research. Front. Oncol. 8:313. doi: 10.3389/fonc.2018.00313

Lake, I. R., Hooper, L., Abdelhamid, A., Bentham, G., Boxall, A. B. A., Draper, A., et al. (2012). Climate change and food security: health impacts in developed countries. Environ. Health Perspect. 120, 1520-1526. doi: 10.1289/ehp.1104424

Leon, D. A. (2008). Cities, urbanization and health. Int. J. Epidemiol. 37, 4-8. doi: 10.1093/ije/dym271

Liu, C., Chen, R., Sera, F., Vicedo-Cabrera, A. M., Guo, Y., Tong, S., et al. (2019). Ambient particulate air pollution and daily mortality in 652 cities. N. Engl. J. Med. 381, 705-715. doi: 10.1056/NEJMoa1817364

Mitchell, D., Heaviside, C., Vardoulakis, S., Huntingford, C., Masato, G., Guillod, B. P., et al. (2016). Attributing human mortality during extreme heatwaves to anthropogenic climate change. Environ. Res. Lett. 11:074006. doi: 10.1088/1748-9326/11/7/074006

Mitsakou, C., Dimitroulopoulou, S., Heaviside, C., Katsouyanni, K., Samoli, E., Rodopoulou, S., et al. (2019). Environmental public health risks in European metropolitan areas within the EURO-HEALTHY study. Sci. Total Environ. 658, 1630-1639. doi: 10.1016/j.scitotenv.2018.12.130

Morawska, L., Miller, W., Riley, M., Vardoulakis, S., Zhu, Y., Marks, G., et al. (2019). Towards Urbanome the genome of the city to enhance the form and function of future cities. Nat. Commun. 10:4014. doi: 10.1038/s41467-019-11972-6

Pope, C. A., Ezzati, M., and Dockery, D. W. (2009). Fine-particulate air pollution and life expectancy in the United States. N. Engl. J. Med. 360, 376-386. doi: 10.1056/NEJMsa0805646

Salmond, J. A., Tadaki, M., Vardoulakis, S., Arbuthnott, K., Coutts, A., Demuzere, M., et al. (2016). Health and climate related ecosystem services provided by street trees in the urban environment. Environ. Health 15, 95-111. doi: 10.1186/s12940-016-0103-6

Scovronick, N., Budolfson, M., Dennig, F., Errickson, F., Fleurbaey, M., Peng, W., et al. (2019). The impact of human health co-benefits on evaluations of global climate policy. Nat. Commun. 10:2095. doi: 10.1038/s41467-01909499-x

Sverdlik, A. (2011). Ill-health and poverty: a literature review on health in informal settlements. Environ. Urbanization 23, 123-155. doi: 10.1177/0956247811398604

The Lancet (2012). Shaping cities for health: a UCL/Lancet Commission. Lancet 379:2023. doi: 10.1016/S0140-6736(12)60870-8

Vardoulakis, S., Dear, K., Hajat, S., Heaviside, C., Eggen, B., and McMichael, A. J. (2014). Comparative assessment of the effects of climate change on heat and cold related mortality in the UK and Australia. Environ. Health Perspect. 122, 1285-1292. doi: 10.1289/ehp.1307524 
Vardoulakis, S., Dear, K., and Wilkinson, P. (2016). Challenges and Opportunities for Urban Environmental Health and Sustainability: the HEALTHYPOLIS initiative. Environ. Health 15, 1-4. doi: 10.1186/s12940-0160096-1

Vardoulakis, S., Dimitroulopoulou, S., Thornes, J. E., Lai, K.M., Taylor, J., Myers, I., et al. (2015). Impact of climate change on the domestic indoor environment and associated health risks in the UK. Environ. Int. 85, 299-313. doi: 10.1016/j.envint.2015.09.010

Vardoulakis, S., Kettle, R., Cosford, P., Lincoln, P., Holgate, S., Grigg, J., et al. (2018). Local action on outdoor air pollution to improve health. Int. J. Public Health 63, 557-565. doi: 10.1007/s00038-018-1104-8

Wang, L., Zhong, B., Vardoulakis, S., Zhang, F., Pilot, E., Li, Y., et al. (2016). Air quality strategies on public health and health equity in Europe - a systematic review. Int. J. Environ. Res. Public Health 13:E1196. doi: 10.3390/ijerph13121196

Wang, Y., Zhang, X., Liao, W., Wu, J., Yang, X., Shui, W., et al. (2018). Investigating impact of waste reuse on the sustainability of municipal solid waste (MSW) incineration industry using emergy approach: a case study from Sichuan province, China. Waste Manag. 77, 252-267. doi: 10.1016/j.wasman.2018.04.003

World Health Organization (2016a). Preventing Disease Through Healthy Environments: A Global Assessment of the Burden of Disease From Environmental Risks. World Health Organization. Available online at: https:// www.who.int/quantifying_ehimpacts/publications/preventing-disease/en/ (accessed November 22, 2019).
World Health Organization (2016b). Health as the Pulse of the New Urban Agenda. Quito: World Health Organization's report to HABITAT III - United Nations Conference on Housing and Sustainable Urban Development. Available online at: https://www.who.int/phe/publications/urban-health/en/ (accessed November 22, 2019).

World Health Organization (2019). Urban Health Initiative - Catalysing Change. World Health Organization. Available online at: https://www. who.int/sustainable-development/cities/about/en/ (accessed November 22, 2019).

Wu, F., Jacobs, D., Mitchell, C., Miller, D., and Karol, M. H. (2007). Improving indoor environmental quality for public health: impediments and policy recommendations. Environ. Health Perspect. 115, 953-957. doi: 10.1289/ehp. 8986

Conflict of Interest: The authors declare that the research was conducted in the absence of any commercial or financial relationships that could be construed as a potential conflict of interest.

Copyright (c) 2019 Vardoulakis and Kinney. This is an open-access article distributed under the terms of the Creative Commons Attribution License (CC BY). The use, distribution or reproduction in other forums is permitted, provided the original author(s) and the copyright owner(s) are credited and that the original publication in this journal is cited, in accordance with accepted academic practice. No use, distribution or reproduction is permitted which does not comply with these terms. 